\title{
Presentación
}

\section{Mensaje de la REDIECH}

Los seres humanos tenemos la costumbre de celebrar los nacimientos. El Primer Congreso de Investigación Educativa es la ceremonia del nacimiento de un fenómeno que esperamos cambie la realidad educativa en nuestra entidad. Podemos decir claramente que a partir de este evento nace el campo de la investigación educativa con sus tensiones, sus disputas, sus vaivenes y sus agentes claramente identificados.

Al realizar el Primer Congreso de Investigación Educativa en Chihuahua, la Red de Investigadores Educativos Chihuahua A.C. (REDIECH) cumple con uno de sus objetivos: "Promover y organizar eventos y encuentros académicos, orientados hacia la comunicación y la discusión entre las y los investigadores, así como a la difusión de los productos de investigación". Pero más allá del cumplimiento de metas de nuestra asociación, con la realización de dicho Congreso, el campo de la investigación educativa rompe con el campo político y el campo institucional, de tal manera que los investigadores educativos asistimos de forma autónoma a un espacio plural de dialogo, de discusión, de debate y de reflexión en torno al conocimiento científico relacionado con la educación.

Este Congreso fue convocado y organizado por una red de investigadores educativos que pertenecemos a diferentes instituciones y agrupaciones, con diferentes afiliaciones profesionales, políticas y personales, que trabajamos en diferentes ámbitos de la educación del estado, y sin importarnos si nuestros colegas investigadores pertenecen o no a esta Red fueron invitados a participar del diálogo en este espacio. Los recursos financieros que lo sustentan provienen del Fondo Mixto CONACYT-Gobierno del Estado; la labor organizativa es mérito de decenas de entusiastas académicas y académicos, que compartimos un solo propósito: construir un escenario autónomo que nos permita a todos, miembros o no de la REDIECH, reunirnos con otros investigadores para compartir entre pares los hallazgos, las experiencias y las propuestas sobre la realidad educativa chihuahuense. Los trabajos que se publican en esta revista constatan esta diversidad y pluralidad que caracteriza a nuestro estado. Lo único que nos iguala es nuestro trabajo de investigación educativa en la entidad.

El proceso de organización del evento vivió diferentes etapas y actividades que dimensionan la valía de la participación de los integrantes de la REDIECH. Hago un reconocimiento desde aquí para todas y todos los involucrados, porque ninguno de ellos estuvo sujeto a presiones o estímulos institucionales: se hizo porque era algo que queríamos hacer. Espero que encuentren en el logro de la tarea, la motivación personal para seguir adelante en esta aventura que juntos emprendimos hace más de dos años, y que continuaremos en el 2014 cuando sea tiempo de convocar al 2o Congreso de Investigación Educativa en Estado de Chihuahua.

Una de las enormes fortalezas del Congreso y de los trabajos que se presentan, fue el proceso de dictaminación al que se sujetaron. El Comité Científico se dio a la tarea de invitar a más de 200 investigadores e investigadoras del campo de la investigación nacional, de las cuales el $57 \%$ pertenecen al Sistema Nacional de Investigadores (SNI) y el $68 \%$ tienen membresía en el Consejo 
Mexicano de Investigación Educativa (COMIE). Fue interesante la diversidad de procedencia de las instituciones, entidades y niveles de los dictaminadores: los hay provenientes de las máximas casas de estudio de entidades lejanas en el país y los hubo también ubicados en escuelas del nivel básico de nuestra entidad. La cifra de recepción de trabajos fue también muy importante: 107. Para ser la primera experiencia de un evento desde los académicos, es un buen número.

Hubo una aceptación del 59\%. En la revista se publican únicamente 63 trabajos en dos números correspondientes a 2012 y 2013 , mismos que fueron aceptados en al menos dos de las tres revisiones ciegas que se les practicaron.

En resumen, hubo conjunción de perspectivas y rigurosidad en la evaluación. La dictaminación y parte de la organización, se facilitó gracias al Sistema de Gestión de Conocimiento e Información del Consejo Mexicano de Investigación Educativa A.C. (COMIE) a quien agradecemos enormemente el apoyo brindado. La REDIECH reconoce especialmente la hospitalidad diligente de la Institución Benemérita y Centenaria Escuela
Normal del Estado (IByCENECH) que acogió con beneplácito nuestra propuesta.

Finalmente vemos reflejada en nuestra Red, la configuración de los fractales, en los que: la acción de uno solo de sus elementos tiene repercusiones inimaginables. Los fractales son complicados paisajes que se esconden, detrás de un universo capaz de expandir un átomo a tamaños siderales, ahí donde nunca antes se había dirigido la vista. Así, el paisaje de la investigación educativa en Chihuahua que está ayudando a construir la REDIECH, nunca había sido imaginado en nuestra entidad: lograr que sus actores se identificaran como investigadores; que se hiciera este tipo de eventos sin la lógica de alguna institución educativa de por medio y sin los grandes recursos económicos; que agentes de la investigación de ópticas institucionales, formaciones e intereses tan disímbolos, trabajaran armoniosamente y en franca colaboración, evidencia el genuino interés de aprender y compartir saberes y experiencias de la comunidad de investigadores e investigadoras chihuahuenses.

\section{Dra. Romelia Hinojosa Luján \\ Presidenta de la REDIECH \\ Octubre de 2012}

